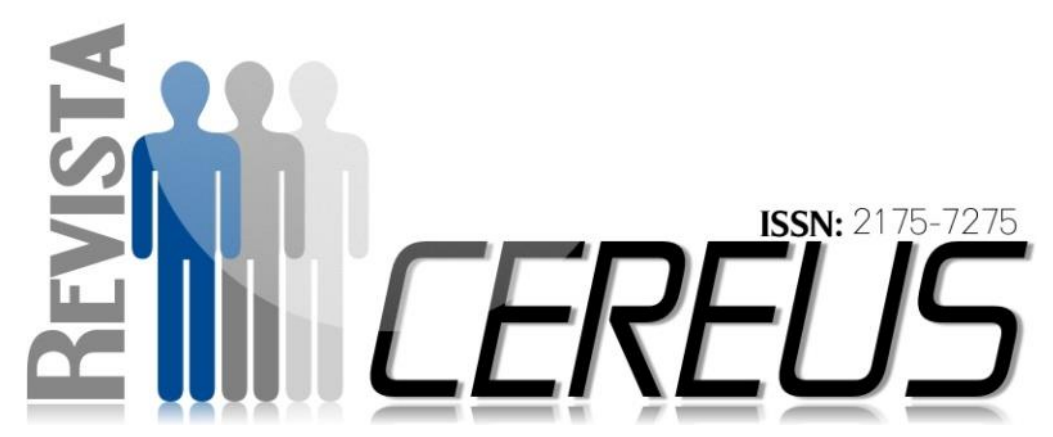

DOI: 10.18605/2175-7275/cereus.v9nep142-157.

\title{
INCIDÊNCIA DAS INDICAÇÕES DE CESARIANAS REALIZADAS EM UM HOSPITAL PÚBLICO DO ESTADO DO TOCANTINS: ALGUNS QUESTIONAMENTOS A PARTIR DE UMA VISÃO SOCIOPRAGMÁTICA
}

\author{
MONTEIRO, Adriano Kerles de Deus ${ }^{1}$ \\ PEREIRA, Bruno Gomes²
}

\section{RESUMO}

Este artigo retrata as complicações obstétricas que geram motivos para a indicação de uma cesariana, bem como Iteratividade, Sofrimento Fetal, DPP, PP, Pré-eclâmpsia e entre outros. O estudo identificou a incidência das indicações de cesariana realizadas em um Hospital Público da Região Norte do Estado do Tocantins. Para tanto, foi utilizado como local de pesquisa o um Hospital de Referencia do Estado, o mesmo atende pessoas de toda a região do Bico do Papagaio e de cidades de estados circunvizinhos e por ter uma quantidade significativa de parto por mês. Trata-se de uma pesquisa documental, descritiva de abordagem quantitativa. O estudo mostrou que há um alto índice de cesariana realizadas na instituição hospitalar estudada e que as ${ }^{1}$ Mestrando em Ciências da Educação pela FIAVEC. Graduado em Enfermagem pela FABIC. Especialista em Enfermagem Obstétrica pelo INESPO. Graduado em Medicina pela UMAX.

${ }^{2}$ Doutor em Ensino de Língua e Literatura (Estudos Linguísticos) pela UFT. Docente do programa de Mestrado em Ciências da Religião da FIAVEC e do UNITPAC (Araguaína). E-mail: brunogomespereira_30@hotmail.com.

v. 9, n. esp, ago/dez. 2017 UnirG, Gurupi, TO, Brasil 
indicações mais relevantes foram a Iteratividade, sofrimento fetal e desproporção céfalo pélvica.

Palavras chave: Cesariana; Indicação; Hospital público; Enfermagem

INCIDENCE OF THE INDICATIONS OF CESARIANS DONE IN A PUBLIC HOSPITAL OF THE STATE OF TOCANTINS: SOME QUESTIONS FROM A SOCIOPRAGMATIC VISION ABSTRACT

This article describes the obstetric complications that are reasons for the indication of a cesarean section, as well as Iterativity, Fetal Suffering, DPP, PP, Pre-eclampsia and others. The study aimed to identify the incidence of cesarean section indications performed at a Public Hospital in the Northern Region of the State of Tocantins. For this purpose, a State Reference Hospital was used as a research site, it serves people from all over the Bico do Papagaio region and from cities in surrounding states and for having a significant amount of childbirth per month. It is a documentary research, descriptive of a quantitative approach. The study showed that there was a high rate of cesarean section performed in the hospital institution studied and that the most relevant indications were Iphericity, fetal distress and cephalic pelvic disproportion.

Keywords: Cesarean section. Indication. Public hospital. Nursing. 


\section{INTRODUÇÃO}

A cesariana, em seus primórdios, era acompanhada de altas taxas de morbidade e mortalidade materna, principalmente por falhas de conhecimentos técnicos. A partir do aperfeiçoamento das técnicas, esta começou a substituir o fórceps e suas taxas foram elevando-se devido às indicações por apresentações pélvicas, à melhoria do diagnóstico de sofrimento fetal e às cesarianas iterativas. Um estudo recente mostrou que doze entre dezenove países latino-americanos estudados apresentavam taxas de cesariana acima do proposto pela OMS, variando entre 16,8\% (Colômbia) e $40 \%$ (Chile).

No mesmo estudo, o Brasil ocupava a segunda posição, com $27,1 \%$. Dados do Departamento de Informática do SUS (DATASUS) apontaram taxas de cesariana crescentes desde o ano de 1994, 32\%, chegando a 40,2\% em 1996. Após esse período, houve redução até 1999, quando as taxas foram de 36,9\%, aumentando, novamente, para 39,9\% em de 2002.

O fato da pesquisa ter sido desenvolvida em um lócus específico, confere a esta investigação um caráter pragmático que a diferencia totalmente de outras pesquisas semelhantes.

Existem várias explicações tradicionais sobre a origem do termo Cesárea, pode ter sido atribuído ao nascimento de Caio Júlio Cesar nascido de um parto abdominal. Entretanto, uma vez que a mãe sobreviveu ao parto, e que numa cirurgia abdominal seria fatal naquela época, essa explicação não é plausível. E também pode ter vindo do latim caedere que significa "cortar". (BADER, 2007, p. 397). A cesariana, cesárea ou tomotocia é o ato cirúrgico que consiste em incisar o abdome e a parede do útero para libertar o concepto aí desenvolvido (REZENDE, 2005).

$$
\text { Ziegel e Crannley }
$$
complementam que as cesarianas com o passar dos anos se tornaram mais seguras, e a incidência dessa operação tem aumentado nos últimos anos. Bader (2007) diz que em 2000, 23\% dos partos nos EUA ocorreram por cesárea.

Segundo Smith (2004), um sistema de manejo do trabalho de parto pode ser projetado para promover um trabalho de parto efetivo com o objetivo de reduzir a taxa de cesariana. São 
utilizadas algumas técnica baseadas em trabalhos exercidos a Irlanda que incluem: Educação à paciente, critérios para diagnóstico de comprometimento fetal, cuidados individuais da enfermagem durante 0 trabalho de parto, uso de infusão de ocitocina em altas doses (quando necessário), auditoria cuidadosa de todos os partos operatórios.

As cesarianas apresentam uma taxa de mortalidade materna e fetal maior que a dos partos normais, mas quando há complicações; a operação é frequentemente mais segura para a mãe e o bebê que um parto vaginal difícil (ZIEGEL; CRANNLEY, 1986).

A operação cesariana é realizada em ambiente cirúrgico, utilizando anti-sepsia e campos operatórios, a paciente é posta em posição de trendelenburg moderada, utiliza-se, para abertura do ventre, a incisão de Phannnenstiel (REZENDE 2005).

Bader (2007) acrescenta que a incisão de Phannnenstiel é uma incisão horizontal feita embaixo do abdome. Ela é muito efetiva para maioria das cirurgias pélvicas, incluindo a cesariana, pois oferece a vantagem de ter uma baixa taxa de hérnia pósoperatória.

A cesariana é indicada em casos de paciente anteriormente cesariada, desproporção cefalopelvica, discinesias, distorcias das partes moles, apresentação anômala, placenta prévia, descolamento prematuro de placenta, toxemia tardia, pós-maturidade, diabetes, doença hemolítica perinatal, sofrimento fetal agudo ou crônico, morte habitual do feto ou recém-nascido, prolapso e procidencia de cordão, primiparidade idosa, história de partos laboriosos, antecedentes de operações plásticas ginecológicas, câncer genital, atos tocúrgicos intentados e frustados per vaginam e morte da gestante com feto presumidamente vivo (cesárea post mortem) (REZENDE, 2005, p. 608)

A maior incidência nas indicações de cesárea está na desproporção cefalopélvica, onde há uma desproporcionalidade entre a bacia e o feto, e cesárea anterior (iteratividade) sendo utilizada na prevenção de rotura uterina. 


\section{RESULTADOS E DISCUSSÃO}

Em primeiro lugar, procurou-se identificar a incidência de cesarianas e o motivo da indicação da mesma. As indicações mais comuns foram sofrimento fetal, Desproporção Cefalopélvica, Iteratividade, PréEclâmpsia Aminiorrexe Prematura, Feto Pélvico, Controle da Natalidade,
Parada de Progressão, Descolamento Prematura de Placenta, Placenta Prévia, Atonia uterina, Gemelaridade e Oligoidrâmnio. Foi realizado 302 partos (cesariana e natural) no período de 15/07 a 15/08 de 2011, portanto foi possível demonstrar por meio dos gráficos a seguir os resultados obtidos:

Gráfico 1- Percentual na taxa de cesarianas ocorrido no Hospital Regional de Augustinópolis-TO.

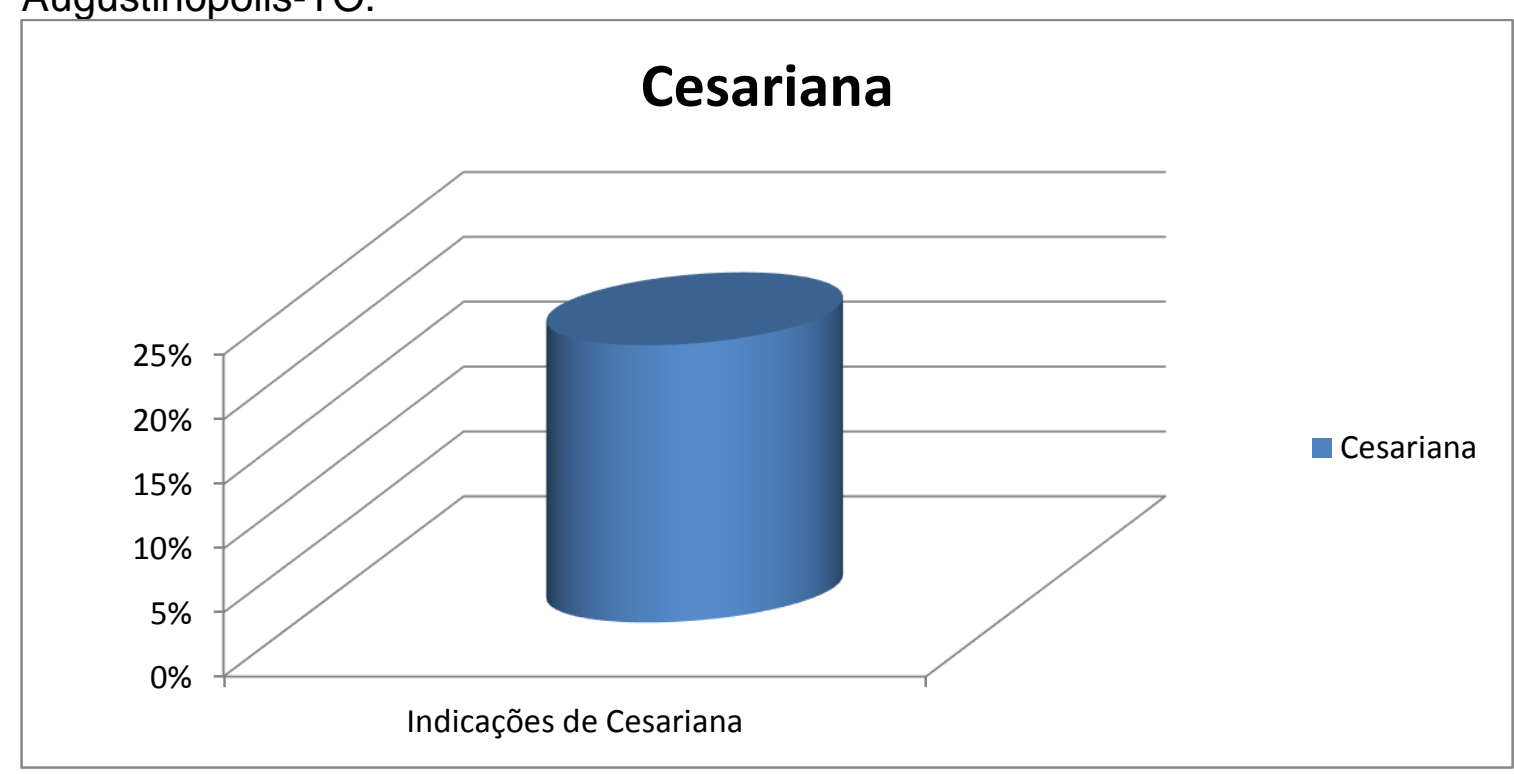

Fonte: pesquisa de campo

Por meio dos dados obtidos, a incidência de cesarianas está acima do valor estabelecido pelo OMS, ficando com $21.52 \%$ de todos os partos ocorridos durante um período de 30 dias no Hospital Regional de Augustinópolis-TO.

Fiocruz (2007), segundo a Organização Mundial de Saúde, não existem evidências que justifiquem, em qualquer população, taxas de cesariana superiores a $15 \%$. No Brasil, no ano de 2000 a 2003 estava com taxas próximas a $40 \%$, conforme dados do DATASUS, A portaria GM nำ66/00, que propôs o Pacto Nacional pela Redução da Taxa de Cesárea, sugere que todas as unidades da Federação 
alcancem a taxa de $25 \%$, no máximo, até 2007.

Gráfico 2- Percentual de indicação de cesariana por sofrimento fetal ocorrido no Hospital Regional de Augustinópolis-TO.

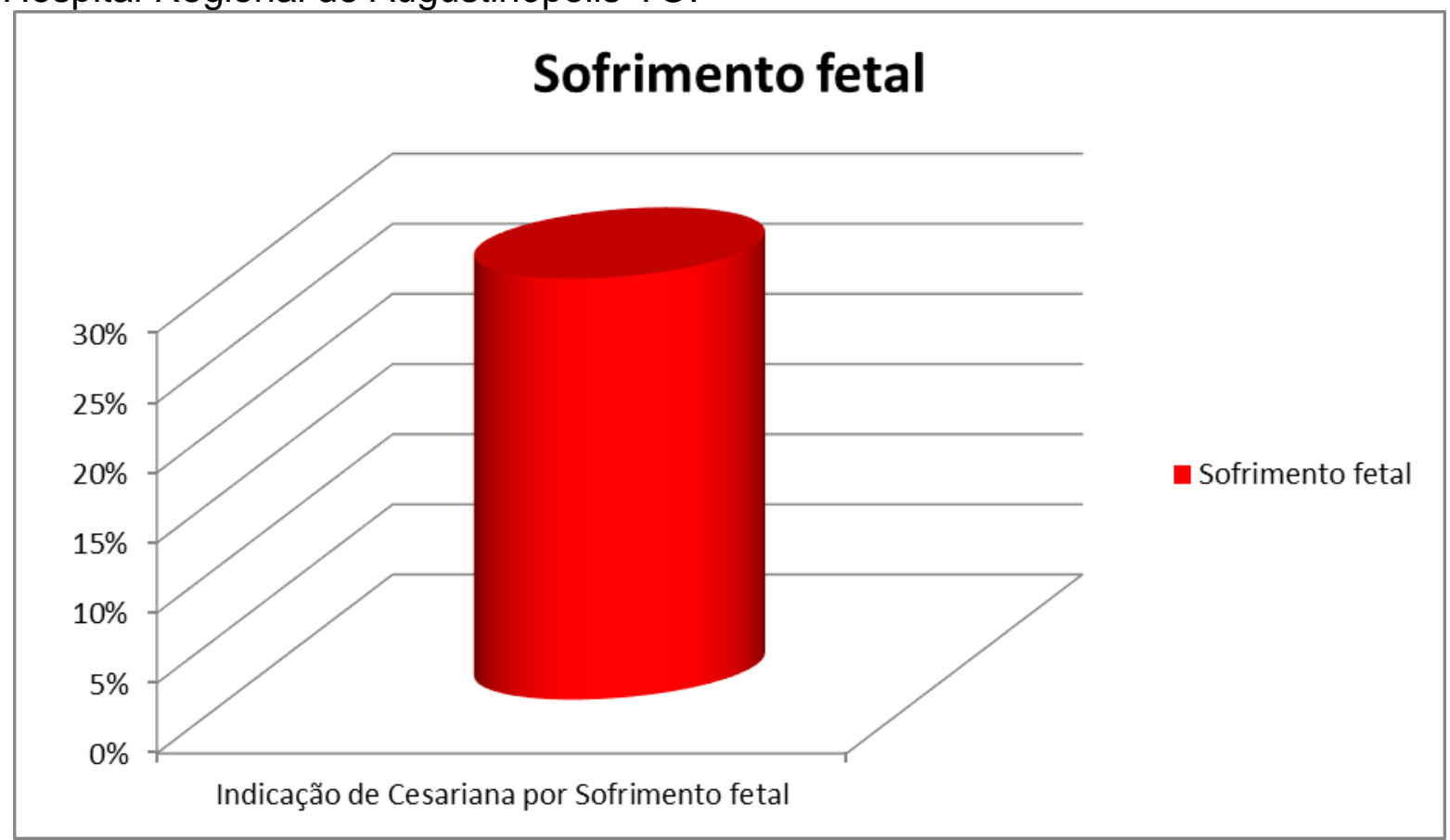

Fonte: Pesquisa de campo

Segundo Cabral (2002), o comprometimento da vitalidade fetal freqüentemente exige a interrupção da gestação por via abdominal. Nos casos de sofrimento crônico, que podem ser secundários a doenças maternas ou fetais, a capacidade do feto em suportar as mudanças induzidas nas trocas gasosas existentes durante as contrações uterinas pode estar comprometida.

Ziegel e Crannley (1986, p. 424) confirmam ao dizer que quando há presença de sofrimento fetal durante 0 trabalho de parto, é indicado a cesariana. Sofrimento fetal é um termo que pode abranger várias condições que sugerem que o feto estará em perigo se 0 parto for retardado. Alterações persistentes na freqüência e no ritmo do coração do feto, que incluem taquicardia, desacelerações tardias, bradicardia intensa ou perda da variabilidade do batimento são consideradas alterações graves que requerem parto precoce, especialmente se não respondem ao tratamento. 
De acordo com os dados da pesquisa, a indicação mais relevante para a ocorrência de uma cesariana foi sofrimento fetal $(28 \%)$, sabe-se que instalado o quadro de sofrimento fetal seja por pós-datismo ou trabalho de parto prolongado é recomendado uma cesariana de emergência, pois o feto está em situação de risco.

Gráfico 3- Percentual de indicação de cesariana por Desproporção céfalopélvica ocorrido no Hospital Regional de Augustinópolis-TO

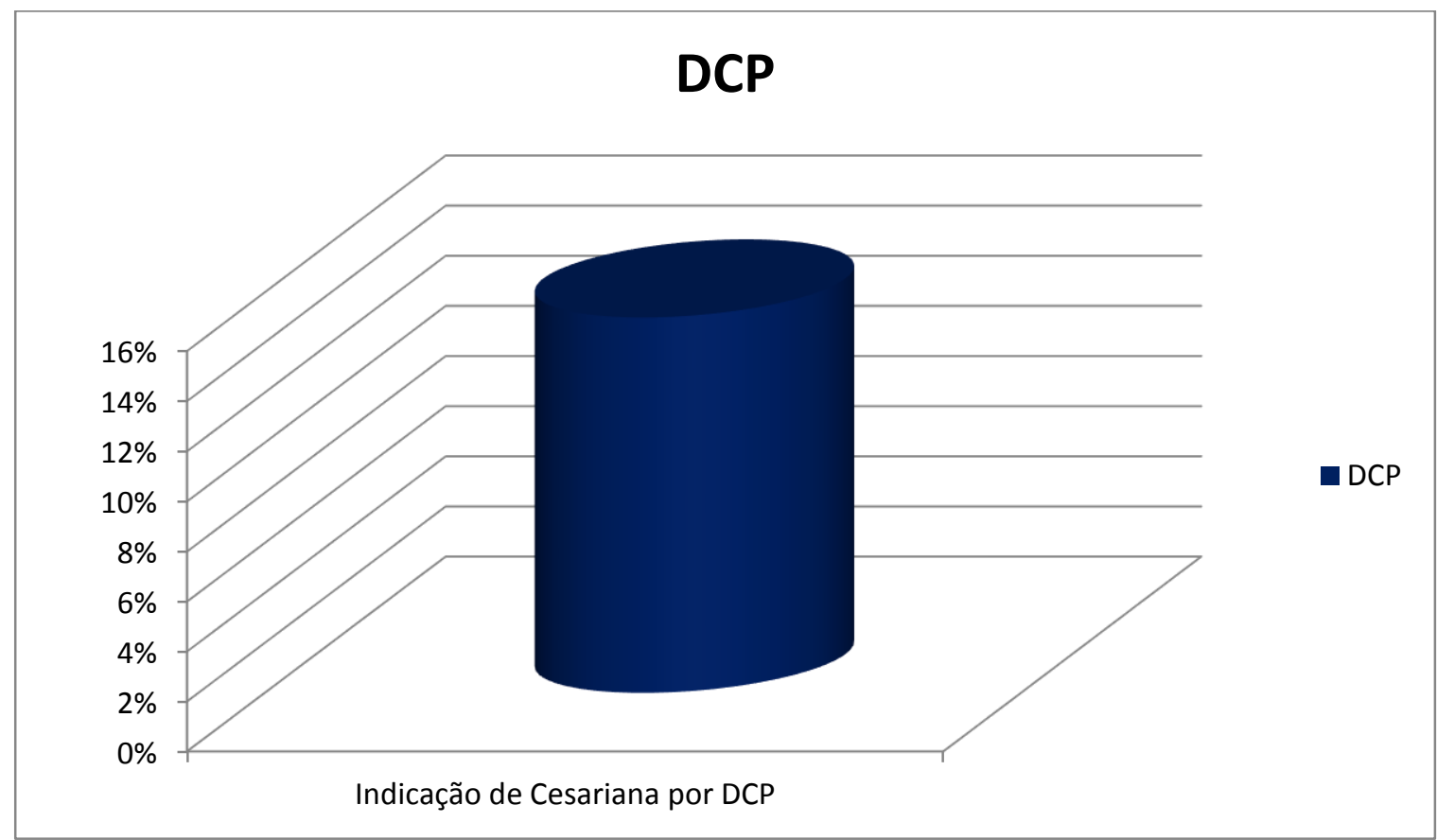

Fonte: Pesquisa de campo

Como o nome já diz, é uma desproporção entre o tamanho da pelve e a cabeça do feto, incluindo sua moldabilidade. Segundo Rezende (2006), a falta de equilíbrio entre o móvel e trajeto decorre da relativa O trajeto (bacia óssea) e o concepto deve está em harmonia, quando a bacia é de menor que o feto exigüidade do segundo em relação ao primeiro. Por sua vez, o componente fetal da desproporção pode ser o pólo craniano nas apresentações cefálicas, o tronco nas córmica e, nas nádegas, o segmento cefálico (cabeça derradeira). não haverá passagem, e o parto deve ser via abdominal, percebe-se que 15\% dos partos cesarianas foram por DCP. 
Por essa razão, não se deve adiar a cesariana, após feito o diagnóstico, deve-se logo encaminhar a paciente para a cirurgia, pois a DCP pode levar o feto a um sofrimento fetal que também é indicação de cesariana por emergência.

Cabral (2002) diz que depois de confirmado a desproporção feto-pélvica e a falta de progressão na descida do pólo cefálico, estará indicado o parto por via abdominal. O diagnóstico de DCP deve ser feita através dos seguintes procedimentos Rezende (2006) Avaliação clínica da cabeça fetal, radiologia, ressonância magnética, ultra-sonografia, prova de trabalho de parto e semiologia da pelve.

Gráfico 4- Percentual de indicação de cesariana por Iteratividade ocorrido no Hospital Regional de Augustinópolis-TO

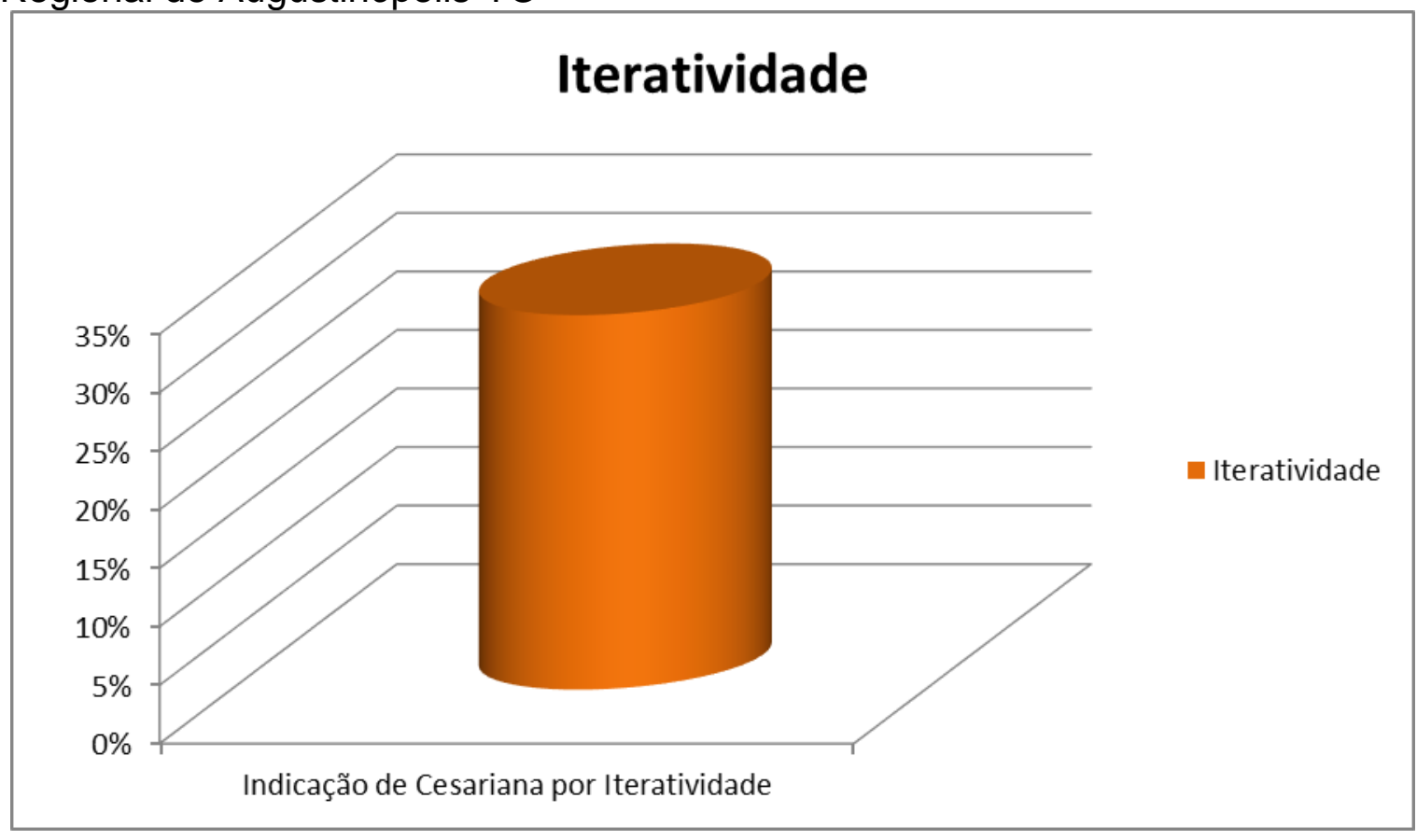

Fonte: Pesquisa de campo

Conforme Ziegel e Crannley (1986), muitos médicos apoiam o princípio "uma vez uma cesariana, sempre uma cesariana", mas deve-se fazer análise sobre as condições que envolveram a cesariana original
Para Bader (2007), a preocupação sobre a ruptura da cicatriz uterina levou à recomendação de ao se tentar um trabalho de parto depois de uma cesariana, e sim fazer uma outra cesárea. Nas ultimas décadas, tal filosofia tem sido revista. Atualmente, a 
maioria das mulheres com cesárea prévia é considerada candidata para o parto vaginal; A ruptura uterina é uma complicação obstétrica que coloca o feto, o útero e a mãe em perigo.

Antecedente de cesárea é uma das causas de maior incidência de parto abdominal, de acordo com a pesquisa, a iteratividade ficou com $32 \%$ dos partos, confirmando-se o princípio "uma vez uma cesariana, sempre uma cesariana", essa teoria visa a prevenção de ruptura uterina, muitos médicos preferem realizar a cesariana quando se tem cesárea anterior, muitos não querem arriscar pois o útero fica fragilizado, talvez não suportando um trabalho de parto.

Gráfico 5- Percentual de indicação de cesariana por Pré-eclâmpsia ocorrido no Hospital Regional de Augustinópolis-TO

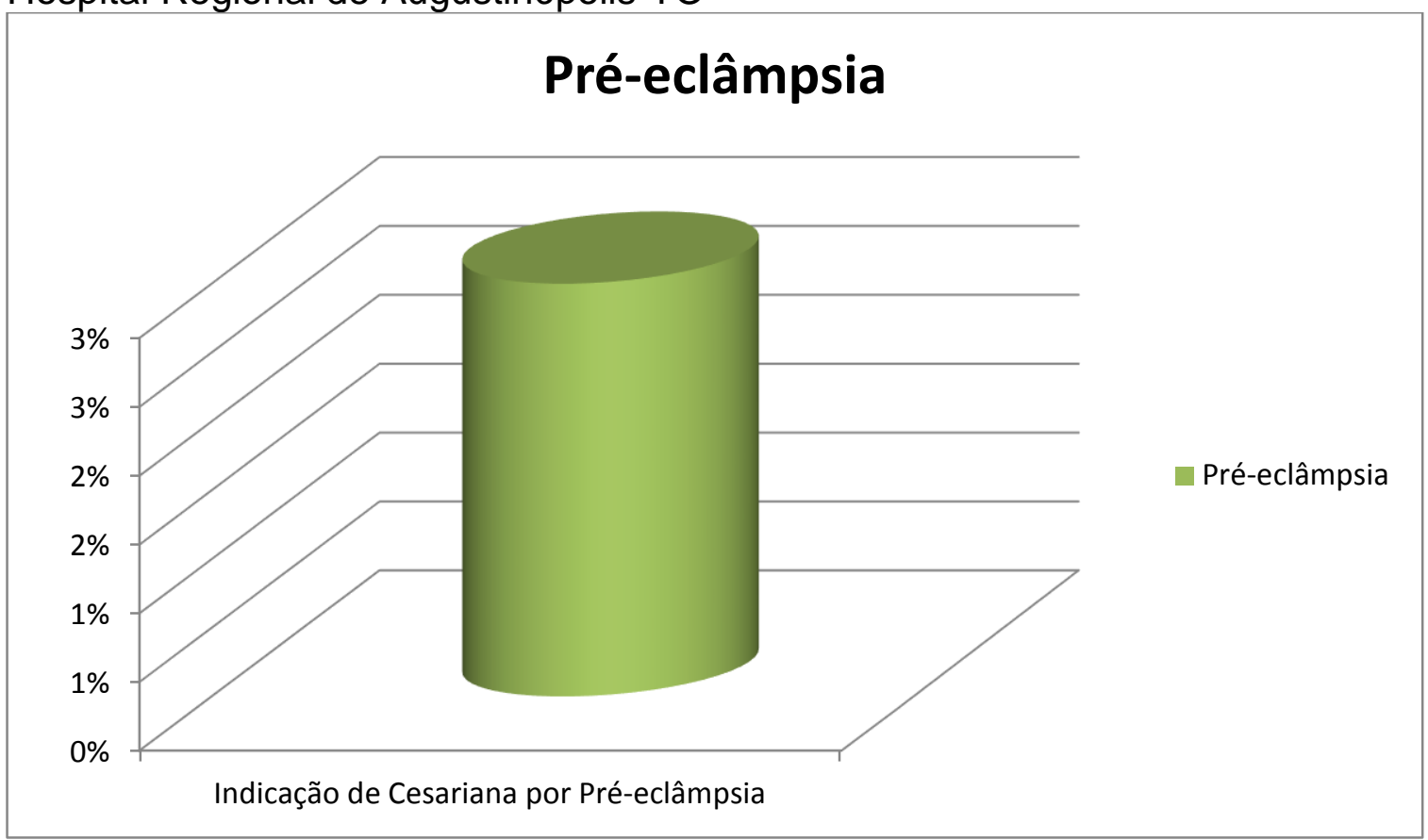

Fonte: Pesquisa de campo

Segundo Silva (2009), a préeclâmpsia é caracteriza pela tríade hipertensão arterial, edema e proteinúria (albiminúria), com aparecimento após a $20^{\text {a }}$ semana da gravidez.
Para Bader (2007), as complicações que podem surgir ao feto são: restrição do crescimento, oligoidrâmnio, infarto placentário, descolamento prematuro de placenta, conseqüências de prematuridade insuficiência útero-placentaria e morte 
perinatal. $E$ as conseqüências que podem acontecer com mãe são: Manifestações do SNC, incluindo convulsões e acidente vascular cerebrovascular, CIVD e suas complicações, insuficiência renal, insuficiência ou ruptura hepática e morte.

A medicina não dispõe de medicamentos para a cura da toxemia Brochini (2005), a partindo dessa afirmação, Ziegel e Crannley (1986) afirmam que a única cura para a toxemia é o parto. Por essa razão, se o parto ao é aconselhável devido à imaturidade fetal, os esforços são dirigidos no sentido de controlar os sintomas, a fim de melhorar a condição materna e fetal até que o parto possa ser tentado.

Segundo Rezende Montenegro (2006), qualquer forma clínica de toxemia com o feto maduro (34-37 semanas) obriga à interrupção da gravidez. O processo toxêmico só se cura com o parto.

De acordo com a pesquisa, a pré-eclâmpsia ficou com $3.5 \%$ das indicações de cesárea, isso está atribuído a um impedimento de complicações materno-fetais, pois o parto é a conduta mais segura frente às pacientes com toxemia. Também é possível observar uma taxa elevada (oito casos) de pacientes com préeclâmpsia atendidas no H.R.A.

Gráfico 6 - Percentual de indicação de cesariana por Aminiorrexe Prematura ocorrido no Hospital Regional de Augustinópolis-TO

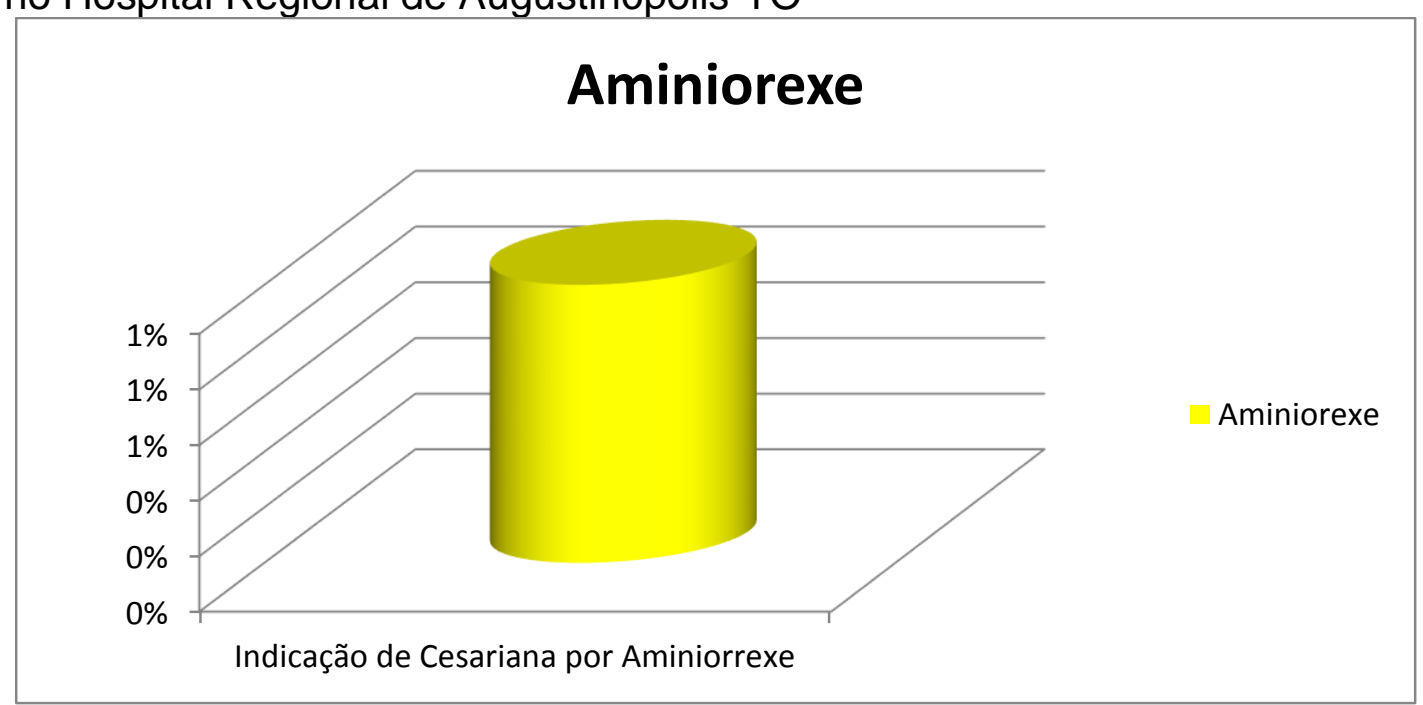

Segundo Rezende (2005), antes de apresentar sistematização de conduta, apenas com fim didático, cumpre fazer face e tentar responder, afirmativamente, às seguintes questões:

- Está confirmado o diagnóstico de aminiorrexe prematura? 
- Qual a idade gestacional?

- São os toques vaginais recomendados?

- Deve-se tentar inibir a ameaça de trabalho de parto?

- $\quad$ Deve-se induzir o parto?

- Cultura positiva de secreções cervical deveria motivar indução?

- Deve-se induzir maturidade pulmonar fetal com corticosteróides?

- Qual deve ser a via de terminação do parto?

Tem por objetivo principal reduzir os riscos decorrentes da coriomnionite, do sofrimento fetal intraparto, da tocurgia e, nas gestações muito pré-termo, da hipoplasia pulmonar.

Segundo Cabral (2002), os acidentes funiculares, a compressão do cordão umbilical por aminiorrexe prematura ou oligoidrâmnio ou circular de cordão são fatores importantes na redução da oxigenação fetal. Confirmando o quadro de sofrimento, só resta ultimar a extração fetal.

Nota-se por meio dos dados obtidos, a aminorrexe prematura corresponde a $1.5 \%$ das indicações de cesariana. Esta conduta objetiva-se a prevenção de sofrimento fetal e/ou infecção (corioamnionite).

Gráfico 7 - Percentual de indicação de cesariana por Feto Pélvico ocorrido no Hospital Regional de Augustinópolis-TO

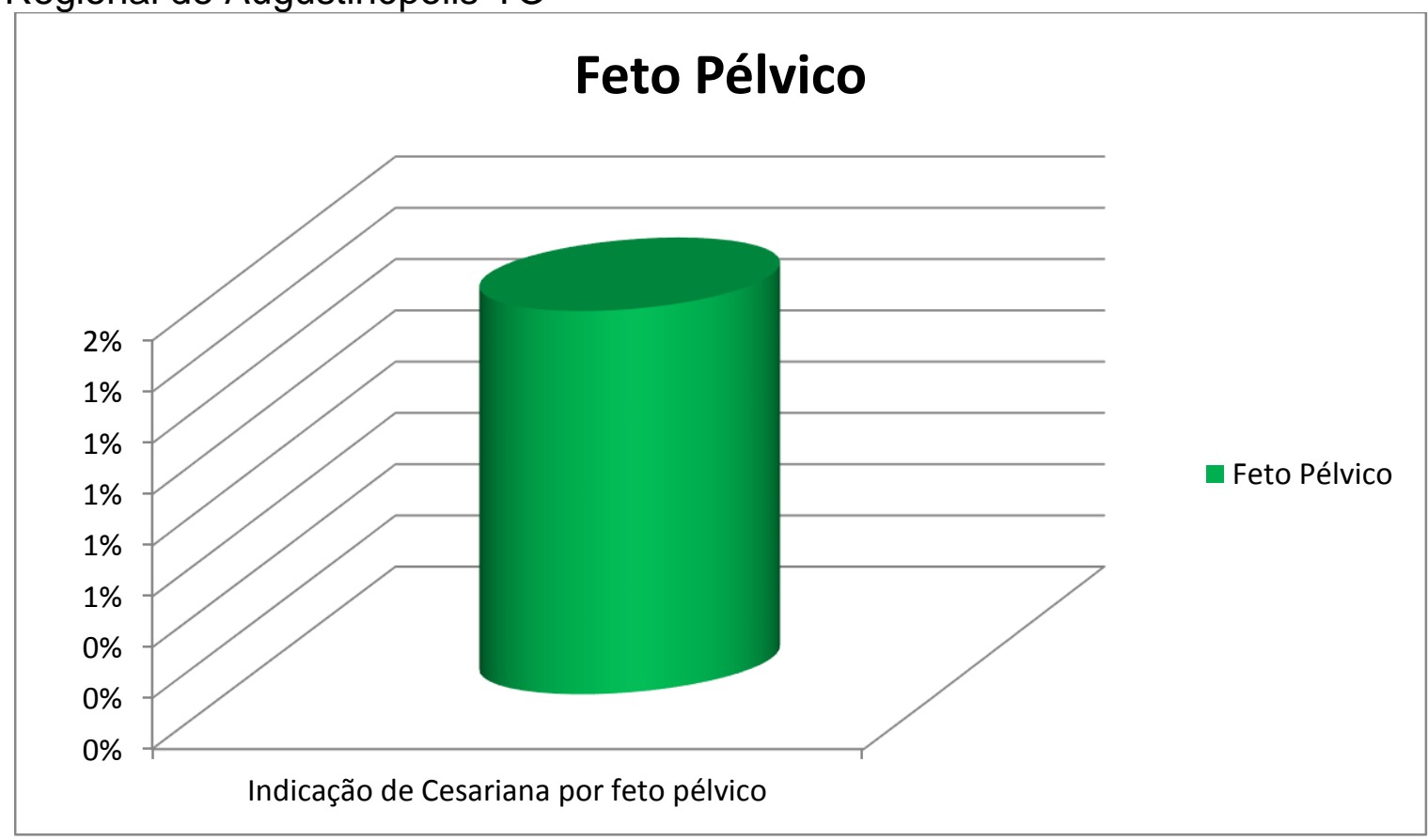

Fonte: Pesquisa de campo 
É inquestionável o fato de existir maior liberalidade na indicação da via abdominal quando se diagnostica a apresentação pélvica. (CABRAL 2002). Observa-se que $1.5 \%$ dos partos foram por motivo de apresentação pélvica, sendo este considerado uma complicação fetal, na maioria das vezes quando se tem apresentação pélvica é indicado 0 parto cesariana, não deixando de ser possível o parto ocorrer por via vaginal, isso vai depender da experiência do obstetra e do quadro clínico do parto.

Gráfico 8 - Percentual de indicação de cesariana por Controle de Natalidade ocorrido no Hospital Regional de Augustinópolis-TO

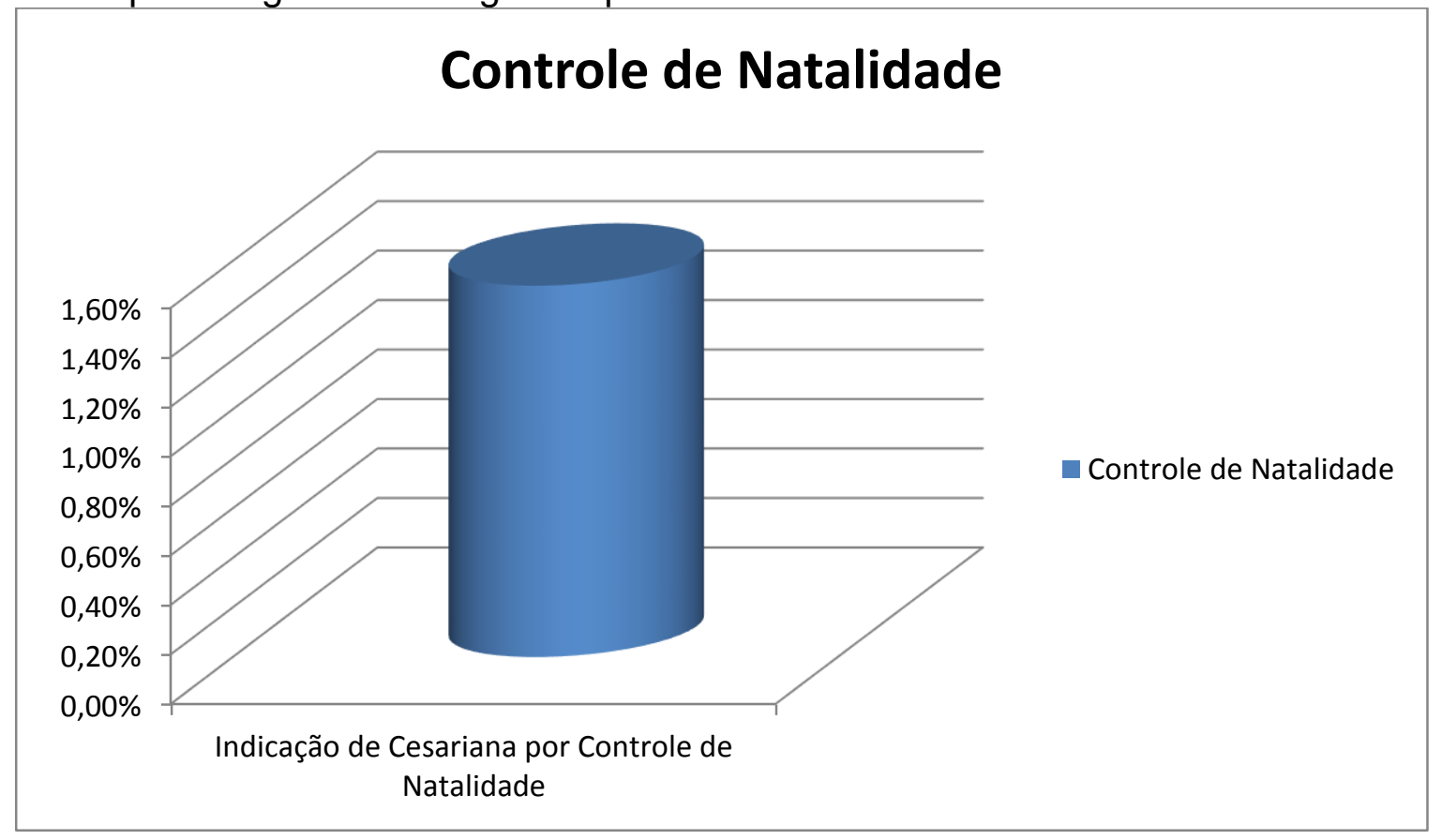

Fonte: Pesquisa de campo

Em 1997, o Ministério da Saúde, por meio da Portaria $\mathrm{n}^{\circ} .1442 \mathrm{e}$, posteriormente, da Portaria $n^{\circ} .0483$ incluiu a laqueadura tubária e a vasectomia no grupo de procedimentos cirúrgicos do Sistema Único de Saúde (SUS), permitindo a esterilização nas seguintes situações: no caso de homens e mulheres maiores de 25 anos ou com pelo menos dois filhos vivos, e no caso de risco para a mãe ou para o filho, tendo testemunhado em relatório escrito e assinado por dois médicos, observando um prazo mínimo de 60 dias entre a manifestação da vontade do casal e a realização da cirurgia (MARCOLINO, 2004). 
Muitas vezes, quando a paciente deseja fazer uma esterilização logo após a última gestação, opta-se então por uma cesariana para então realizar a laqueadura tubária. O controle da natalidade utilizando a laqueadura é bastante comum no Brasil, e de acordo com a pesquisa, realizou-se $1.5 \%$ de cesarianas pelo mesmo motivo.

Gráfico 9 - Percentual de indicação de cesariana por Oligoidrâmnio, Parada de Progressão, Descolamento Prematuro de Placenta e Atonia Uterina ocorrido no Hospital Regional de Augustinópolis-TO

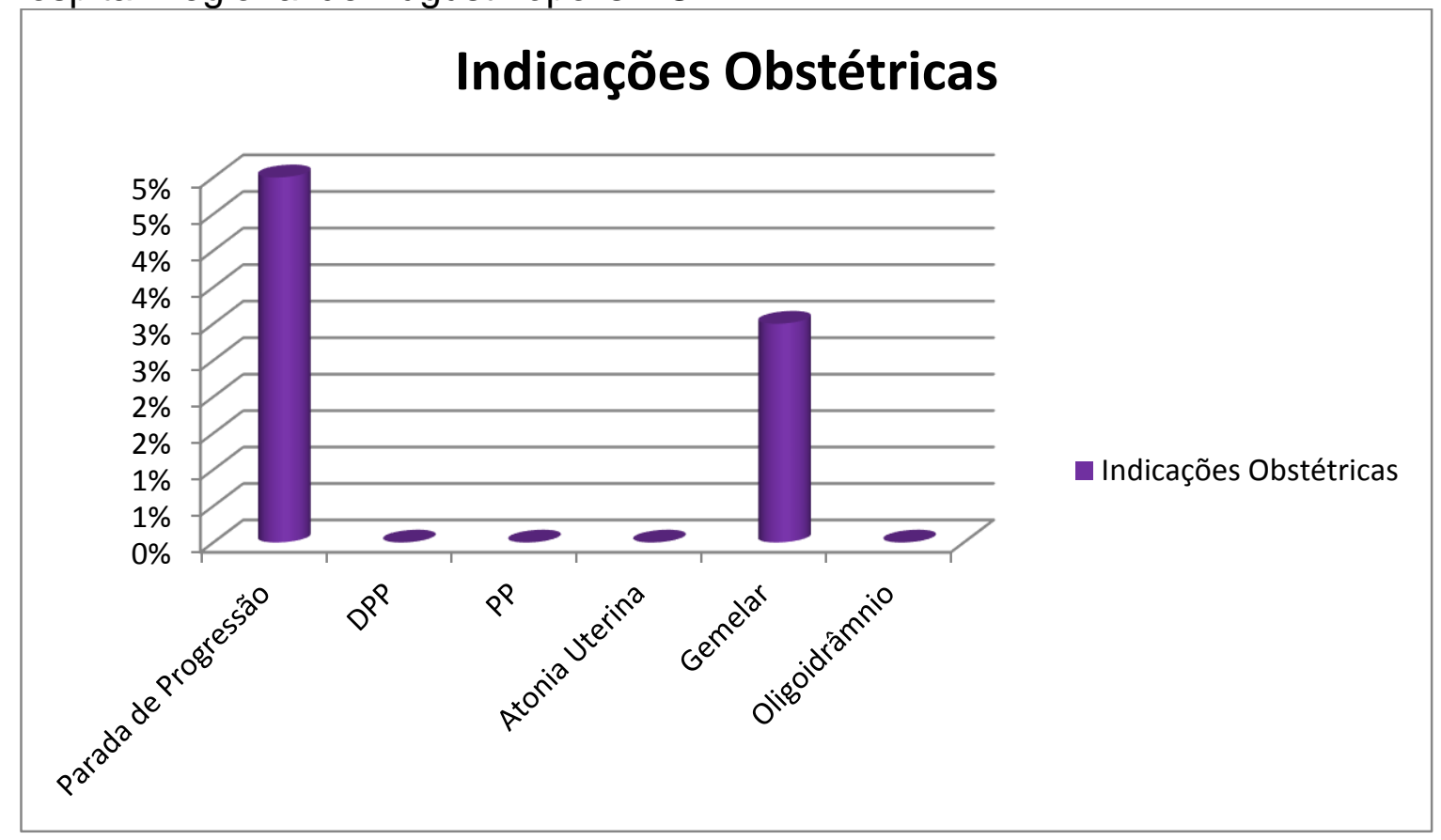

Fonte: Pesquisa de campo

Smith (2004) descreve que Placenta prévia é quando há implantação da placenta em localização que recobre todo ou uma parte, do orifício cervical.

Percebe-se, por meio do gráfico, que a placenta prévia ficou com $4.5 \%$ das indicações. Montenegro (2008) o tratamento ativo da PP depois de documentada a maturidade fetal tornase compulsória a interrupção imediata da prenhez. A cesárea é a via quase obrigatória para a interrupção da gravidez.

Outra indicação observada foi o Descolamento Prematuro de PlacentaDPP, que ficou com $1.5 \%$ das indicações de cesariana. Rezende (2005) conceitua DPP como a separação da placenta implantada no corpo do útero, antes do nascimento do 
feto, em gestação de 20 ou mais semanas completas.

Segundo Montenegro (2008) o tratamento obstétrico, estando o concepto vivo, é a operação cesariana. Outra indicação encontrada é a parada de progressão; para Cabral (2002) é considerado parada de progressão quando o feto atinge o estreito médio e permanecem também por período de 30 minutos na variedade de posição transversa, sem realizar a rotação interna.

Segundo o Gráfico, observa-se que $5 \%$ dos partos foi por parada de progressão, a mesma não deixa de ser uma desproporção cefalopélvica, pois

\section{CONSIDERAÇÕES FINAIS}

Os resultados da pesquisa nos permitiu verificar um alto índice de cesariana (21.52\%) no Hospital Regional estudado, e os motivos para explicá-las são as causas obstétricas.

O estudo mostrou uma diversidade de indicações de cesarianas, a maioria indicações obstétricas que são pertencentes a alguma anormalidade do processo fisiológico do parto, impedindo a realização do parto natural. Mas há uma interrupção de descida no estreito médio da bacia óssea.

$\mathrm{Na}$ atonia uterina ocasionalmente o útero apresenta dificuldade de se contrair em freqüência e intensidade adequada no período expulsivo; uma das causas é a exaustão do músculo uterino, que ocorre principalmente quando o tempo de evolução está demasiadamente prolongado.

Percebe-se que os casos de atonia uterina foi a menos encontrada atingindo apenas $1.5 \%$ dos partos cesariana, isso pode ser atribuído às condutas obstétrica bem sucedidas na indução ao parto.

também foi possível constatar que há também um número de indicação por fatores extrínsecos, como o controle de natalidade utilizando-se a laquiadura das trompas.

A pesquisa mostrou que a maior parte das indicações está atribuído à iteratividade, uma vez que a parturiente foi submetida a cesariana em gestação anterior, na seguinte provavelmente será realizado outra cesariana por medida de segurança evitando assim 
uma rotura uterina/hemorragia e conseqüentemente morte materna.

É indagável a utilização de cesariana posterior a outra cesariana, pois muitos profissionais da área médica preferem realizar a cesariana a um parto natural, pois economia tempo e por ter uma lucratividade maior; mesmo o parto natural ser mais favorável financeiramente.

É possível observar também que houve um número significativo de indicação por sofrimento fetal, isso nos faz pensar que o acompanhamento com a gestante a termo não está sendo totalmente eficaz.

Em suma, as indicações de cesariana encontradas nessa pesquisa são inevitáveis, uma vez que são indicações obstétricas, não dependendo de profissionais que realizarão ou acompanharão o parto, mas depende das circunstâncias fisiológicas; visando 0 bem estar materno e fetal.

\section{REFERÊNCIAS}

BADER, Thomas J. Segredos em Ginecologia e Obstetrícia: respostas necessárias ao dia-a-dia em rounds, na clínica, em exames orais e escritos; tradução Ricardo Savaris. 3 ed. Atualizada- Porto Alegre: Artmed, 2007.

BROCHINI, Mário. Hipertensão na Gravidez. Atualizações e Reciclagens, coordenador científico: prof. Paulo Roberto Bastos Canella. Rio de Janeiro: Atual, 2005.

CABRAL, Antônuio Carlos vieira. Manual de assistência ao Parto. São Paulo: Atheneu, 2002

CRANLEY, Mecca S, Enfermagem Obstétrica.8 ed. Guanabara Koogan: Rio de Janeiro. 1986

MARCOLINO, Clarice. Planejamento familiar e laqueadura tubária: análise do trabaho de uma equipe de saúde. Rio de Janeiro 2004

MONTENEGRO, Carlos Antônio Barbosa. Rezende. Obstetrícia Fundamental . 11 ed. - Rio de Janeiro: Guanabara Koogan, 2008.

REZENDE, Jorge de. Obstetrícia Fundamental. 10 ed.-Rio de janeiro: Guanabara Koogan, 2005.

REZENDE, Jorge de. Obstetrícia Fundamental. 10 ed.-Rio de janeiro: Guanabara Koogan, 2006. 
SILVA, Janize C. Manual Obstétrico: guia prático para a enfermagem, 2 ed. rev. rev.e ampl. - São Paulo: Corpus, 2009.

SMITH. Roger P. Ginecologia e obstetrícia de Netter. Porto Alegre: Artmed, 2004

Recebido em: 21/09/2017

Aprovado em: 21/02/2018 